Aim of the study: Hepatocellular carcinoma suppressor 1 (HCCS1) has been identified as a tumor suppressor gene in the high-frequency loss of heterozygosity $(\mathrm{LOH})$ region on chromosome 17p13.3 in hepatocellular carcinoma (HCC). There was also a high frequency of $\mathrm{LOH}$ on chromosome 17p13.3 in non-small cell lung cancer (NSCLC). Therefore, the aim of this study was to explore the expression of HCCS1 in NSCLC as well as its clinical significance.

Material and methods: Real-time PCR and immunohistochemistry were performed to detect the expression level of HCCS1 mRNA and protein in NSCLC and noncancerous tissues, respectively. Further, we explored the relationship between HCCS1 expression and various clinical features in NSCLC.

Results: The mRNA and protein expression of HCCS1 were both significantly lower in NSCLC samples than those in noncancerous tissues. That is, the mRNA level of HCCS1 was $0.0044 \pm 0.0036$ and $0.0067 \pm 0.0054$ in NSCLC samples and noncancerous tissues, respectively. The protein level of HCCS1 was $4.67 \pm 1.15$ and $6.13 \pm 1.24$ in NSCLC samples and noncancerous tissues, respectively. Importantly, this difference in expression was significantly correlated with tumor lymph node metastasis (TNM) in NSCLC $(p<0.05)$, but not with gender and age of the patients, pathological types, TNM stages, or grades of cancers $(p>0.05)$. Conclusion: Our results suggest that HCCS1 may be involved in NSCLC carcinogenesis.

Key words: HCCS1, non-small cell lung cancer, loss of heterozygosity.

\section{Expression and clinical significance of HCCS1 in non-small cell lung cancer}

\author{
Shen Xiao-Yong ${ }^{1}$ Lin Zhi-Feng', Lu Fan-zhen'1, Ruan Zhen², Zhen Jian², \\ Huang Hai-long², Ju Chao-qiang ${ }^{2}$
}

1Department of Thoracic Surgery, The Huadong Hospital, Shanghai Fudan University, Shanghai, China

2Department of Thoracic Surgery, Shanghai First People's Hospital, School of Medicine, Shanghai Jiaotong University, Shanghai, China

Lin Zhi-Feng and Shen Xiao-Yong should be regarded as co-first authors

\section{Introduction}

Lung cancer is one of the most common malignancies and has been the leading cause of cancer-related deaths in the world [1]. Fine deleted mapping studies found that loss of heterozygosity $(\mathrm{LOH})$ was frequently present on the chromosome 17p13.3 region in lung cancer, which is independent of and distal to the $\mathrm{p} 53$ gene at 17p13.1. This indicates that some unidentified genes may reside on these deleted regions and play an important role in progression and differentiation of lung carcinogenesis [2-4]. Therefore, recent studies pay more attention to identify the lung cancer-related gene in the 17 p13.3 region.

Of them, HIC-1 (hypermethylated in cancer-1), a candidate tumor suppressor gene, has been identified in this region, which is telomeric from TP53 and often deleted in surgically resected lung cancers. The reduced expression of the $\mathrm{HIC}-1$ gene in the tumor had a direct link with the clinical outcome, such as short survival [5]. The 14-3-3gene, which also resides within the commonly deleted region at 17p13.3 in lung cancers, was found homozygously deleted in two SCLC cell lines. The introduction of 14-3-3 induced significantly restored G2 checkpoint responses, which resulted in the reduction of mitotic cells as well as of aberrant mitotic figures in the X-ray-irradiated 14-3-3-null SCLC cell line [6]. A novel gene, LOST1, was recently shown to be disrupted by the homozygous deletion at 17p13.3. Significantly reduced expression of the LOST1 gene was detected in $69 \%$ of lung cancer specimens [7].

Hepatocellular carcinoma suppressor 1 (HCCS1) is also a novel tumor suppressor gene that has been identified in high-frequency loss of heterozygosity on chromosome 17p13.3 in HCC [8]. However, there has been no report of HCCS1 in lung cancer. Thus, in this study, we aim to explore the HCCS1 expression in NSCLC and further evaluate its clinical significance.

\section{Material and methods}

Tissue sample

Thirty-one resected NSCLC specimens and matched noncancerous tissues were obtained from the First People's Hospital (Shanghai, China) and the Huashan Hospital (Shanghai, China) from April 2010 to December 2010. The specimens were divided into two equal parts; one was immediately immersed in liquid N2 and the other fixed in 10\% formalin. The clinical features of these patients are listed in Table 1. All of the patients have no history of chemotherapy or radiotherapy before the operation.

\section{Total RNA extraction and cDNA synthesis}

Total RNA was isolated from NSCLC specimens and noncancerous tissues according to the protocols of the Triblue system (Shenergy Biocolor, Shanghai, China). A $50 \mathrm{mg}$ frozen tissue sample was ground into a fine powder with a pre-cooled pestle and mortar under liquid $\mathrm{N}_{2}$. The powder was transferred 
Table 1. The relationship between HCCS1 mRNA expression and various clinical parameters in NSCLC

\begin{tabular}{|c|c|c|c|c|c|}
\hline \multirow{2}{*}{\multicolumn{2}{|c|}{ Clinical parameter }} & \multicolumn{4}{|c|}{ HCCS1 mRNA expression } \\
\hline & & $\mathrm{N}$ & $\mathrm{T} \geq \mathrm{N}$ & $\mathrm{T}<\mathrm{N}$ & $p$ \\
\hline \multirow[t]{2}{*}{ gender } & male & $14(54 \%)$ & 3 & 11 & $>0.05$ \\
\hline & female & $12(46 \%)$ & 3 & 9 & \\
\hline \multirow[t]{2}{*}{ age/year } & $\leq 60$ & $15(58 \%)$ & 4 & 11 & $>0.05$ \\
\hline & $>60$ & $11(42 \%)$ & 2 & 9 & \\
\hline \multirow{2}{*}{$\begin{array}{l}\text { pathological } \\
\text { type }\end{array}$} & squamous cell carcinoma & $3(12 \%)$ & 1 & 2 & $>0.05$ \\
\hline & adenocarcinoma & $23(88 \%)$ & 5 & 18 & \\
\hline \multirow{2}{*}{$\begin{array}{l}\text { lymph nodes } \\
\text { metastasis }\end{array}$} & NO & $12(46 \%)$ & 6 & 6 & $<0.05$ \\
\hline & N1-N3 & $14(54 \%)$ & 0 & 14 & \\
\hline \multirow[t]{2}{*}{ TNM stage } & $|-| \mid$ & $16(62 \%)$ & 5 & 11 & $>0.05$ \\
\hline & III-IV & $10(38 \%)$ & 1 & 9 & \\
\hline \multirow[t]{2}{*}{ tumor grade } & high-middle & $23(88 \%)$ & 4 & 19 & $>0.05$ \\
\hline & low & $3(12 \%)$ & 2 & 1 & \\
\hline
\end{tabular}

into a $1.5 \mathrm{ml}$ centrifuge tube and mixed with $1 \mathrm{ml}$ Triblue buffer and $200 \mu \mathrm{l}$ chloroform. After centrifuging at $12000 \mathrm{rpm}$ for $10 \mathrm{~min}$, RNA was precipitated from the aqueous phase by adding 3-fold volume of isopropanol. The RNA pellet was washed with $200 \mu 175 \%$ (v/v) ethanol and dissolved in RNasefree water. The RNA purity and concentration were determined by spectrophotometric absorbance at 260 and $280 \mathrm{~nm} .1 \mu \mathrm{g}$ RNA was used to synthesize cDNA with Random Primers primers and M-MLV Reverse Transcriptase (Promega, Madison, USA). The $25 \mu \mathrm{l}$ PCR reaction mixture contained $5 \mu \mathrm{l}$ $5 \times$ RT Buffer, $2 \mu$ ldNTPs $(10 \mathrm{mmol} / \mathrm{l}, 0.6 \mu$ l RNase inhibitor, $1 \mu$ l Random Primers $(25 \mu \mathrm{M}), 1 \mu$ l Reverse Transcriptase, and $15.4 \mu \mathrm{l}$ RNase-free $\mathrm{H}_{2} \mathrm{O}$. The PCR condition was $37^{\circ} \mathrm{C}$ for $60 \mathrm{~min}, 85^{\circ} \mathrm{C}$ for $10 \mathrm{~min}$, and $4^{\circ} \mathrm{C}$ for $5 \mathrm{~min}$.

\section{Real time quantitative PCR}

The quantitative PCR was performed in an IQ5 Multicolor Real-Time PCR Detection System (Bio-Rad) and the HCCS1 gene expression levels were determined by comparison with the GAPDH gene. The amplification product was 240 bp for GAPDH (forward primer: 5'-GGTGAAGGTCGGAGTCAACGGA-3', backward primer: 5'-GAGGGATCTCGCTCCTGGAAGA-3'); for HCCS1 (hVPS53), 103 bp (forward primer: 5'-CTGCACAGACTGAGTTAGGACA-3', backward primer: 5'-TCTCGTAG AACATTGCTGGGT-3'). The PCR reaction mixture consisted of $10 \mu 12 \times$ ExTaq buffer, $1 \mu \mathrm{l}$ cDNA, each $0.2 \mu \mathrm{l}$ sense and anti-sense primers $(25 \mu \mathrm{mol} / \mathrm{l})$,

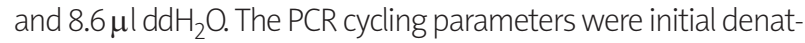
uration at $94^{\circ} \mathrm{C}$ for $30 \mathrm{~s}$; 40 cycles of amplification $\left(94^{\circ} \mathrm{C}\right.$ for $10 \mathrm{~s}, 60^{\circ} \mathrm{C}$ for $60 \mathrm{~s}, 76^{\circ} \mathrm{C}$ for $10 \mathrm{~s}$ with a single fluorescence measurement). Melting curve analysis was conducted $60-95^{\circ} \mathrm{C}$ at a $0.2^{\circ} \mathrm{C} / \mathrm{s}$ melt rate, and finally a cooling step to $60^{\circ} \mathrm{C}$. The relative $\mathrm{mRNA}$ expression was determined by the expression $2^{-\Delta \Delta \mathrm{ct}}[\Delta \mathrm{Ct}=\mathrm{Ct}(\mathrm{HCCS} 1)-\mathrm{Ct}(\mathrm{GAPDH}), \Delta \Delta \mathrm{Ct}=\Delta \mathrm{Ct}(\mathrm{NSCLC})-$ $-\Delta \mathrm{Ct}$ (noncancerous)].

\section{Immunohistochemistry (IHC) assays}

Formalin-fixed samples were dehydrated with gradient ethanol and embedded in paraffin. The paraffin sections $(4 \mu \mathrm{m})$ were mounted onto poly-lysine-coated glass slides and dried for $1 \mathrm{~h}$ at $60^{\circ} \mathrm{C}$ followed by deparaffinizing and rehydration according to a standard protocol. For antigen retrieval, slides were immersed in sodium citrate buffer ( $\mathrm{pH}$ 6.0) and boiled twice for $5 \mathrm{~min}$ in a microwave oven. The slides were then washed with PBS ( 3 min) twice and treated with $3 \% \mathrm{H}_{2} \mathrm{O}_{2}$ for 10 min to inhibit the endogenous peroxidase. This was followed by incubation with rabbit antihuman HCCS1 primary antibody (Sigma, USA) overnight at $4^{\circ} \mathrm{C}$. After being rinsed in PBS three times for 3 min each, the slides were covered with DAKO EnVision, horseradish peroxidase/DAB (3,3'-diaminobenzidine), Rabbit/Mouse (DAKO, Carpinteria, CA) for $30 \mathrm{~min}$ at room temperature. The slides were developed in substrate-chromogen solution (DAB), counterstained with hematoxylin, and mounted. Faint yellow, tan, and brown color could be observed in cytoplasm under the optical microscope as positive results. The positive cell counting was performed according to the percentage of positive cells in 5 visual fields, that is: 5-25\%, 1 point; $25-50 \%$, 2 points; 50-75\%, 3 points; > 75\%, 4 points. The dyeing degree classification was as follows: faint yellow, 1 point; yellow or deep yellow, 2 points; tan or brown, 3 points. The average protein expression level of HCCS1 was obtained by multiplying positive cell scores and dyeing degree scores. If the difference was more than 1 in the NSCLC and noncancerous tissue, we considered it significant.

\section{Statistical analysis}

All the statistical analysis was performed using SPSS13.0 software. Normal distribution and paired test were used for comparing HCCS1 expression between NSCLC and noncancerous tissue. The relationship between HCCS1 expression and various clinical parameters in NSCLC were evaluated with chi-square statistics; $p<0.05$ was considered as statistically significant.

\section{Results}

\section{HCCS1 mRNA expression in NSCLC and} noncancerous tissue

Quantitative PCR was used to analyze HCCS1 mRNA expression in 26 NSCLC and their matched noncancerous tissues. The results showed that the mRNA level of HCCS1 was $0.0044 \pm 0.0036$ in NSCLC samples, but $0.0067 \pm 0.0054$ in matched noncancerous tissues. This indicated that the expres- 

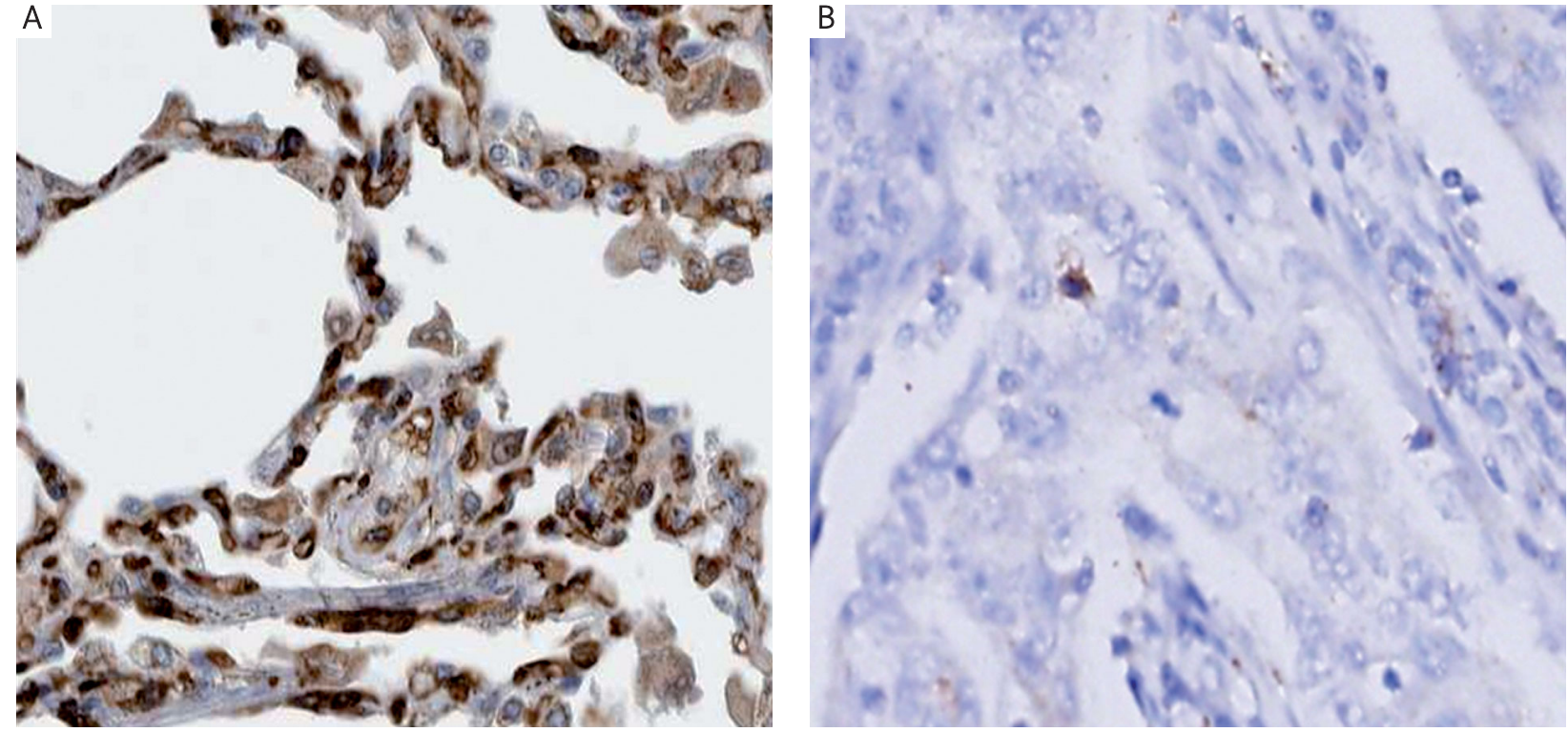

Fig. 1. The protein expression of HCCS1 in NSCLC and noncancerous tissues (400x). A - higher expression in noncancerous tissue; $\mathrm{B}$ - lower expression in NSCLC tissue

sion of HCCS1 mRNA was significantly lower in NSCLC than that in noncancerous tissues ( $p=0.023$ ).

\section{HCCS1 protein expression in NSCLC and noncancerous tissue}

IHC was used to analyze HCCS1 protein expression in 31 NSCLC and their matched noncancerous tissues. The results revealed that the protein level of HCCS1 was $4.67 \pm 1.15$ in NSCLC samples, but $6.13 \pm 1.24$ in matched noncancerous tissues. This suggested that the expression of HCCS1 protein was significantly lower in NSCLC than that in noncancerous tissues ( $p=0.038)$ (Fig. 1).

The relationship between HCCS1 mRNA expression and various clinical parameters in NSCLC

From table 1, we can observe that the HCCS1 mRNA expression was significantly correlated with tumor lymph node metastasis (TNM) in NSCLC ( $p=0.003)$, but not with gender and age of the patients, pathological types, TNM stages, and grades of cancers $(p>0.05)$ (Table 1$)$.

The relationship between HCCS1 protein expression and various clinical parameters in NSCLC

Our results also showed that the HCCS1 protein expression was significantly correlated with tumor lymph node metastasis (TNM) in NSCLC ( $p=0.01)$, but not with gender and age of the patients, pathological types, TNM stages, or grades of cancers $(p>0.05)$ (Table 2$)$.

\section{Discussion}

As a novel tumor suppressor gene, HCCS1 was identified through screening the minimum region of high-frequency loss of heterozygosity on chromosome 17p13.3 and positional cloning in HCC [8-10]. The expression level of HCCS1 in HCC samples was significantly lower than that in noncancerous liver cells. Moreover, expression of the exogenous HCCS1 gene in human hepatocarcinoma cells could remarkably suppress their abilities to develop tumors in nude mice and to form colonies in soft agar [8]. Recently, many studies have also demonstrated that HCCS1 showed reduced expression in other cancer cell lines, such as breast cancer cell lines, HeLa-a cervical cancer cell line [11], and colorectal cancer cells [12].

However, there has been no report on the HCCS1 gene in lung cancer. In this study, we first investigated HCCS1 gene expression in the NSCLC sample by quantitative real time PCR and immunohistochemistry assays. As we expected, the results showed that the mRNA and protein expression of the HCCS1 gene were both significantly lower in the NSCLC sample than those in noncancerous tissues, indicating that HCCS1 may be involved in NSCLC development and progression. Further, we explored the relationship between HCCS1 expression and various clinical parameters in NSCLC. The results indicated that the mRNA and protein expression of HCCS1 were significantly correlated with tumor lymph node metastasis (TNM) in NSCLC $(p<0.05)$, but not with gender and age of the patients, pathological types, TNM stages, or grades of cancers $(p>0.05)$. Taken together, our data suggest that HCCS1 is a promising therapeutic gene for the treatment of lung cancers.

The exact molecular mechanisms of the HCCS1 gene in human cancer remain unknown. It is believed that HCCS1 may be involved in human cancer development through a proapoptosis pathway. The amphipathic tail-anchoring peptide (ATAP) domain of HCCS1 has been demonstrated to induce mitochondrial permeability transition via its amphipathic property that perturbs the integrity of the mitochondrial membrane and leads to caspase-dependent apoptosis that does not require Bax or Bak [13]. It was also found that HCCS1 overexpression may induce lysosomal cathepsin $D$ release into the cytosol and consequently triggers Bax insertion into the mitochondrial membrane, leading to the release of 
Table 2. The relationship between HCCS1 protein expression and various clinical parameters in NSCLC

\begin{tabular}{|c|c|c|c|c|c|}
\hline \multicolumn{2}{|c|}{ Clinical parameter } & \multicolumn{4}{|c|}{ HCCS1 protein expression } \\
\hline & & $\mathrm{N}$ & $\mathrm{T} \geq \mathrm{N}$ & $\mathrm{T}<\mathrm{N}$ & $p$ \\
\hline \multirow[t]{2}{*}{ gender } & male & $16(52 \%)$ & 4 & 12 & $>0.05$ \\
\hline & female & $15(48 \%)$ & 4 & 11 & \\
\hline \multirow[t]{2}{*}{ age (year) } & $\leq 60$ & $19(61 \%)$ & 5 & 14 & $>0.05$ \\
\hline & $>60$ & $12(39 \%)$ & 3 & 9 & \\
\hline \multirow{2}{*}{$\begin{array}{l}\text { pathological } \\
\text { type }\end{array}$} & squamous cell carcinoma & $5(16 \%)$ & 1 & 4 & $>0.05$ \\
\hline & adenocarcinoma & $26(84 \%)$ & 7 & 19 & \\
\hline \multirow{2}{*}{$\begin{array}{l}\text { lymph node } \\
\text { metastasis }\end{array}$} & NO & $15(48 \%)$ & 7 & 8 & $<0.05$ \\
\hline & $\mathrm{N} 1-\mathrm{N} 3$ & $16(52 \%)$ & 1 & 15 & \\
\hline \multirow[t]{2}{*}{ TNM stage } & $|-| \mid$ & $19(61 \%)$ & 7 & 12 & $>0.05$ \\
\hline & III-IV & $12(39 \%)$ & 1 & 11 & \\
\hline \multirow[t]{2}{*}{ tumor grade } & high-middle & $27(87 \%)$ & 6 & 21 & $>0.05$ \\
\hline & low & $4(13 \%)$ & 2 & 2 & \\
\hline
\end{tabular}

cytochrome c. The released cytochrome c activates downstream caspase, resulting in the occurrence of the late stages of apoptosis [11]. Importantly, the disruption of HCCS1 in mice leads to embryonic lethality, accompanied by abnormal labyrinth architecture resulting from the excessive proliferation of trophoblast cells in the placenta [14]. In conclusion, these reports suggest that HCCS1 plays a role in apoptosis regulation and development.

\section{References}

1. Esteller M, Sanchez-Cespedes M, Rosell R, Sidransky D, Baylin SB, Herman JG. Detection of aberrant promoter hypermethylation of tumor suppressor genes in serum DNA from non-small cell lung cancer patients. Cancer Res 1999; 59: 67-70.

2. Takahashi T, Konishi H, Kozaki K, Osada H, Saji S, Takahashi T, Takahashi T. Molecular analysis of a Myc antagonist, ROX/Mnt, at 17p13. 3 in human lung cancers. Jpn J Cancer Res 1998; 89: 347-51.

3. Konishi H, Takahashi T, Kozaki K, et al. Detailed deletion mapping suggests the involvement of a tumor suppressor gene at 17p13. 3 distal to p53, in the pathogenesis of lung cancers. Oncogene 1998; 17: 2095-100.

4. Tsuchiya E, Tanigami A, Ishikawa Y, et al. Three new regions on chromosome 17p13. 3 distal to p53 with possible tumor suppressor gene involvement in lung cancer. Jpn J Cancer Res 2000; 91: 589-96.

5. Hayashi M, Tokuchi Y, Hashimoto T, et al. Reduced HIC-1 gene expres sion in non-small cell lung cancer and its clinical significance. Anti cancer Res 2001; 21: 535-40.

6. Konishi H, Nakagawa T, Harano T, et al. Identification of frequent $\mathrm{G}(2)$ checkpoint impairment and a homozygous deletion of 14-33epsilon at 17p13.3 in small cell lung cancers. Cancer Res 2002; 62: 271-6.

7. Konishi H, Sugiyama M, Mizuno K, Saito H, Yatabe Y, Takahashi T, Osada H, Takahashi T. Detailed characterization of a homozygously deleted region corresponding to a candidate tumor suppressor locus at distal 17p13.3 in human lung cancer. Oncogene 2003; 22: 1892 905

8. Zhao X, Li J, He Y, et al. A novel growth suppressor gene on chromosome 17p13. 3 with a high frequency of mutation in human hepatocellular carcinoma. Cancer Res 2001; 61: 7383-7.

9. Xiao W, Park CK, Park JY, et al. Genetic alterations of the HCCS1 gene in Korean hepatocellular carcinoma. APMIS 2003; 111: 465-73.

10. Li Q, Song L, Zhu J. An analysis of HCCS1 gene mutation and loss of hetrozygosity in hepatocellular carcinoma [J]. Journal of Oncology 2009; 10.
11. Kim TE, Kim YW, Hwang SY, et al. Candidate tumor suppressor, HCCS-1, is downregulated in human cancers and induces apoptosis in cervical cancer. Int J Cancer 2002; 97: 780-6.

12. Gan Y, Gu J, Cai X, Hu J, Liu XY, Zhao X. Adenovirus-mediated HCCS1 overexpression elicits a potent antitumor efficacy on human colorectal cancer and hepatoma cells both in vitro and in vivo. Cancer Gene Ther 2008; 15: 808-16.

13. Ko JK, Choi KH, Pan Z, Lin P, Weisleder N, Kim CW, Ma J. The tailanchoring domain of Bfl1 and HCCS1 targets mitochondrial membrane permeability to induce apoptosis. J Cell Sci 2007; 120 (Pt 16): 2912-23.

14. Gan Y, Zhao X, Hu J, Wang ZG, Zhao XT. HCCS1 overexpression induces apoptosis via cathepsin D and intracellular calcium, and HCCS1 disruption in mice causes placental abnormality. Cell Death Differ 2008; 15: $1481-90$

\section{Address for correspondence}

Lu Fan-zhen MD

Department of Thoracic Surgery

The Huadong Hospital

Shanghai Fudan University

Shanghai, China

e-mail: lufanzhenlfzhzh@hotmail.com

Submitted: $\quad 30.10 .2011$

Accepted: $\quad$ 15.05.2012 